\title{
The machine as psychotherapist: impersonal communication with a machine ${ }^{\dagger}$
}

\author{
Digby Tantam
}

Abstract Machines will replace therapists and counsellors. This was the confident prediction made a decade ago. In this article, I discuss the inherent limitations of machines as conversationalists that have prevented the prediction from coming true. Machines can, however, be exploited to assist therapy and I consider the following digital tools: test administration; managing procedural, symptom-relieving cognitivebehavioural therapies; providing virtual environments for immersive behavioural therapies and for elearning; and assisting training through automated discourse analysis and the use of cognitive maps.

This is the third of four articles by Digby Tantam addressing aspects of electronic media in psychotherapy (see also Tantam, 2006a,b). The fourth article, in which he considers the use of a machine, and often the internet, to mediate between individuals in activities germane to psychotherapy, also appears in this issue. ${ }^{+}$

In one of his first films, THX-1138, George Lucas adapts and extends a film he made as a student at the University of South California in which electronic devices are used to control society and, in particular, to prevent people falling in love. One of the devices used is a machine counsellor that troubled citizens can access from public booths, like telephone booths, dotted throughout the city. The machine counsellor was clearly inspired by the well-known computer program ELIZA, developed by Joseph Weizenbaum (Weizenbaum, 1966).

ELIZA, named after Eliza Doolittle in Shaw's Pygmalion, was designed to support a conversation with a human user. Weizenbaum chose the paradigm of a conversation with a non-directive therapist to minimise the amount of factual data that he had to put into the computer's memory. Instead, it relied on a simple means of parsing sentences, extracting key phrases and then placing them in phrase structures stored in its memory. From the beginning

${ }^{+}$See pp. 427-431, this issue.
Weizenbaum considered ELIZA to be a parody of a therapist, but its performance was superficially convincing and it led some people to hail the imminent replacement of psychotherapists by computers.

ELIZA can be accessed at many sites on the internet, for example http://www-ai.ijs.si/eliza/ eliza.html. Here is a brief interchange that I had with the program:

ELIZA: Hello. I am ELIZA. How can I help you?

Digby: Can I help you?

ELIZA: Do you want to be able to help i?

ELIZA is based on the person-centred counselling technique of repeating with appropriate grammatical modification the last few words of what the client has just said. So,

$\begin{array}{ll}\text { Client: } & \text { I feel so sad } \\ \text { Digby: } & \text { You are feeling sad? } \\ \text { Client: } & \text { Yes. My life is in ruins } \\ \text { Digby: } & \text { You feel your life is in ruins? } \\ \text { and so on. } & \end{array}$

In THX-1138, the hero tells the booth that the city is 'coming apart at the seams', and the booth dutifully rephrases this as 'You feel the city is coming apart at the seams?' even when the audience can see the flames engulfing the neighbourhood.

ELIZA uses 'natural language processing' (i.e. the user and the program interact in ordinary English), and this can be emulated in quite short programs,

\footnotetext{
Digby Tantam is Clinical Professor of Psychotherapy at the University of Sheffield (Centre for the Study of Conflict and Reconciliation, University of Sheffield School of Health and Related Research, 30 Regent Street, Sheffield S6 6GJ, UK. Email: d.tantam@sheffield.ac.uk). $\mathrm{He}$ is Co-Director of the University's Centre for the Study of Conflict and Reconciliation, Director of the Section of Mental Health within the School of Health and Related Research, and Deputy Director of Teaching for the School. He is also an honorary consultant psychotherapist and psychiatrist in Sheffield Care Trust. His current research interests include the evaluation of internet-based learning and teaching.
} 
called chatterbots or chatbots, which learn simple vocabulary and conversational rules. At present chatbots require text in and text out communication, although the most recent version of the Artificial Intelligence Foundations' prizewinning A.L.I.C.E. (Artificial Linguistic Computer Entity) can be trained to recognise a particular voice, and will produce spoken responses rather than text. With advances in natural language processing, it is likely that the training period will become shorter and shorter until it becomes imperceptible.

One common critique of such programs, and indeed of computer interaction in general, is that they are not 'embodied' (for a discussion see Tantam, 2006b). It is worth noting here that computer programs for recognising emotions in faces are being actively developed in many laboratories, as are programs for emulating emotions in computer-generated animation. A simple form of empathy emulation has already undergone a trial (Brave et al, 2005). The use of avatars, virtual bodies, in chat rooms has become standard and avatars nowadays may crudely emulate emotions and produce slightly caricatured non-verbal expressions. Development of the latter is proving easier than the former, but considerable progress has been made on both, driven partly by the resources of the film industry. A.L.I.C.E. herself has a computer-animated face which follows the mouse pointer with suitable eye movements, in itself giving a surprising degree of apparent interaction. George, the instantiation of Jabberwacky, which has won the most recent Loebner prizes, also has a computer generated 'face' that mimics facial expressions.

Computer technology has made less progress in the recognition of facial expression although face recognition itself is well-advanced. It remains unclear whether people will ever respond in quite the same way to something that they see as an animation as to someone that seems to have a real body, that bleeds and suffers.

Early proponents of chatbots thought that they would make counselling and psychotherapy redundant. However, Weizenbaum's experience with ELIZA led him to argue against this assumption (Weizenbaum, 1976). He, like many psychotherapists, believed that a computer would always fail the Turing test (Box 1), that it could so convincingly imitate a human being in its responses to any text input that it would be taken to be a human being. Reasons for failing the Turing test include an inability to be truly generative in response and an inability to have an adequate theory of mind (Saygin et al, 2000). Whether or not computers or other devices will always fail the Turing test for these or other reasons is a matter of prejudice rather than science. However, it is pretty clear that they are nowhere near passing the test at the moment.

\section{Box 1 The Turing machine and Turing test}

Alan Turing, marathon runner, government scientist, mathematician and a member of the famous Enigma code-breaking team, was a member of the Manchester team that developed one of the first digital computers. Two manifestations of his extraordinary ability are the Turing machine and the Turing test.

The universal Turing machine is a mathematical description of the minimum requirements of an imaginary machine that could emulate any computer. One important corollary of the Turing machine is that computers will carry on trying to solve a problem indefinitely or until they find a solution. Computers cannot conclude that a problem is not soluble (not 'computable', to use the mathematical term).

Some 15 years after imagining the Turing machine, Turing turned his attention to what differentiates a human from a machine. $\mathrm{He}$ considered and rejected many of the then current tests of humanity, and proposed his own. He said we have to imagine that we are communicating with either a computer or a person, but that we do not know which. Our only means of communication is by typewritten sheet or, as we would say now, by text message or email. Would we know whether we were communicating with a person or a computer? My summary of the ELIZA dialogue suggests that we would know very quickly, even with the best modern computer and chatbot program. I doubt that anyone imagined a computer passing Turing's test when it was published, but many science fiction books and films now seem less sure.

What computers can do is tirelessly manage rulebound procedures and, apart from usually obvious malfunction, reliably. They have an established place in psychotherapy in the administration and scoring of tests and in delivering psychotherapy procedures.

\section{The machine as tester}

The internet is becoming the most popular means of presenting tests. Creating forms is easy (there are numerous freeware and commercial programs for doing this), they can be accessed via web pages, completed at one's own computer, submitted securely 
using the same methods as secure banking and other commercial transactions, and stored in one of the common server-side databases, such as MySQL or Access, from which they can be downloaded into statistical analysis programs, printed or plotted as graphs. Performance on computer-administered tests is very similar to that on paper-based tests (Epstein \& Klinkenberg, 2001).

However, ease of application and analysis is not psychotherapists' main concern about testing. They are more worried about the validity of testing when it comes to the human issues that psychotherapy addresses. When the tester is human, test interpretation can go beyond simple test scores and take account of the interaction between the tester and the tested. This is not possible on an automated test (Butcher et al, 2004). Nevertheless, in direct comparisons, computer-administered test results are similar to those of tests administered by a human being (Epstein \& Klinkenberg, 2001) and are as acceptable (Mead \& Drasgow, 1993).

\section{Can internet-based tests add anything useful for the psychotherapist?}

Computers have made possible the analysis of complex tests that are more psychotherapy friendly but are prohibitively time-consuming to rate by hand. These include the repertory grid. The ease with which tests can be converted into internet forms has also made tests selected, administered and rated by users widely available. Arguably few of these have any psychotherapeutic significance although some, such as the Myers-Briggs personality indicator (http: / / www.myersbriggs.org), have proven validity even when self-administered, and may serve to interest some internet surfers in psychological matters and psychotherapy. Expert systems, capitalising on the speed and memory of computers, have been slow to penetrate psychotherapy, but are gradually being adopted for treatment selection (e.g. http:/ / www. systematictreatmentselection.com) and for tracking patient progress during therapy.

Computer adaptation is the main advantage of computer-based testing. Computer-adaptive tests are interactive. Item selection can be based on previous item scores and an algorithm, only the most discriminating questions need be asked and only enough need be asked to achieve a predetermined level of accuracy (Wainer, 2000). In a study of 744 participants in depression treatment trials (Gardner et al, 2004), a computer-adapted version of the 21item Beck Depression Inventory showed both high efficiency (asking an average of only 5.6 items) and high accuracy in identifying major depressive episodes and measuring depression severity, making it a useful instrument for clinical practice.
Response to computer-administered tests can be by means of a keyboard, a touch-sensitive screen or mouse clicks on radio buttons. Since computeradaptive tests are always likely to be shorter than their extended paper-based versions, it is likely that they will replace paper-and-pencil tests even in faceto-face situations, and they are ideally suited for use over the telephone. Tests can be administered on any computer with a suitable operating system and many are suitable for hand-held computers or personal digital assistants (PDAs).

It seems likely that computer-adapted tests will gradually replace other testing methods because of their savings in time. However, many psychologists remain sceptical although recognising that computers enable fast testing and early feedback of test scores to patients, which can accelerate the early stages of therapy (Butcher et al, 2004).

Repeat testing has been used as a means of tracking client progress, of predicting outcome, of detecting increased risk of unwanted events such as premature termination of therapy and of auditing professional performance. Owing to its ability to automate both testing and the analysis and feedback of tests, the computer lends itself particularly to such continual monitoring. One such application, the Outcome Questionnaire Analyst, is routinely used by a US managed-care company, PacifiCare Behavioral Health, and embedded into an outcome monitoring and management procedure called Algorithms for Effective Reporting and Treatment (ALERT). Provider groups with exceptional outcomes as reported by ALERT are given bonuses (Percevic et al, 2004). Feedback to individual therapists from computer analyses of pre- and post-session questionnaires completed by their clients can improve client adherence and therefore outcome, presumably as a result of altered therapist behaviour (Whipple et al, 2003). Monitoring of this kind has become a regular feature in other industries and evaluations suggest that it is accepted provided that it is considered fair (Alder \& Ambrose, 2005).

There are other properties of computers that will probably influence test administration and development in the future. These include the ability to construct virtual environments, which carries with it the possibility that instead of answering test questions, individuals being tested could model aspects of their lives by creating environments or maps that simulate their experience of the world.

\section{Anonymity and testing}

One unexpected finding is that computer-based tests are answered more honestly when potentially shameful material is being elicited, including alcohol (Lucas et al, 1977) or drug use, sexual activity, failure 
to take medication (Millstein \& Irwin, 1983), history of sexual abuse (Bagley \& Genuis, 1991) and the frequency of suicidal thoughts (Greist et al, 1973). This may be related to the disembodiment of the medium that I have already discussed.

\section{More about having machine therapy}

So far, the evidence suggests that the technology is not mature enough to allow therapy to be emulated by computer. Few empirical studies of existing computer-administered psychotherapy have been carried out. In one rare study, individuals reporting stress symptoms were randomly allocated to a student acting as a therapist or a student assisting the client to use a computer to follow the Therapeutic Learning Program (Gould, 1989). Improvement in the computer-using group was of the same order as that in the student-therapist group at the end of therapy, but it did not persist at 6 months (Jacobs et al, 2001), suggesting that there were, in fact, substantive differences between the computer and the therapist.

\section{Cognitive-behavioural and other procedural therapies}

The therapy that I have been considering here is of the exploratory kind that leads to personal change or to the re-evaluation of meaning or purpose in life. We have seen that more focused tasks, for example, test administration, can be carried out successfully by a computer loaded with the appropriate software. Psychotherapy aimed at the relief of distress falls into this category, since it follows well-tried procedures that work for most people, irrespective of their personal circumstances. At least some of these procedures can be reduced to algorithms, making them suitable for computer administration. So, can psychotherapy aimed at symptom relief be delivered by computer?

There is considerable evidence that it can. Cavanagh \& Shapiro (2004) performed a metaanalysis of five computer-based treatments for anxiety or depression and found a sizeable effect compared with waiting-list controls. In a detailed analysis of one of the studies included in this metaanalysis, comparing computer-based treatment with standard care, McCrone et al (2004) concluded that there was an $81 \%$ chance that computer-based treatment would be cost-effective.

Following its review of computerised cognitivebehavioural therapy (CCBT) the National Institute for Clinical Excellence (now the National Institute for Health and Clinical Excellence) concluded that

\begin{abstract}
'research suggests that CCBT may be useful for treating anxiety and depression. But at the moment this evidence on how and where CCBT should be delivered is not strong enough for the Institute to recommend introducing CCBT into general use in the NHS' (National Institute for Clinical Excellence, 2002).
\end{abstract}

However, a further review is being conducted and the treatment may be yet recommended. NICE will undoubtedly be considering the assessment report from the School of Health and Related Research at the University of Sheffield (Kaltenthaler et al, 2005). This concludes that 'There is RCT evidence to support the effectiveness of Beating the Blues and FearFighter' (p. iv).

\section{Well-being}

Broadly speaking, health interventions can be considered to be directed towards prevention, towards the reduction of symptoms and disability, or towards increasing positive health or wellbeing. The positive psychology movement has recently grown from research that suggests that the factors conducive to the relief of symptoms are not necessarily those that improve well-being. In essence, depression, anxiety, pain and certain kinds of disability reduce well-being, but the absence of these symptoms does not confer it. The creation of well-being is more related to social relationships, to spirituality and to engagement in life. Positive psychologists have begun to develop web-based methods to help people identify reasons why they do not experience well-being and to recommend things they can do to increase it. Some might argue that these are the latest recruits to the very large body of self-improvement sites on the internet, and it remains to be seen whether positive psychologists, or psychotherapists, do have more to say than spiritual leaders, churches, nutritionists, mediators, family counsellors, clinical and counselling psychologists and others who are already well-represented.

\section{Virtual reality: psychotherapy by immersion}

Immersive virtual environments offer new possibilities for therapy, for example by providing realistic but not actual exposure. This was first exploited in treating fear of flying, where it was but a step on from the flight simulators that were already in use. Virtual environments for psychotherapy are now being developed for conditions such as back pain (Buhrman et al, 2004), fear and avoidance related to speaking in public (Botella et al, 2004), increasing the impact of psychosocial care in breast cancer (Owen et al, 2004), drug misuse (Copeland \& Martin, 
2004), schizophrenia, autism, post-traumatic stress disorder (Wiederhold \& Wiederhold, 2004), eating disorders (Castelnuovo, et al, 2004) (see example at http:/ /www.vepsy.com/2vrtsession.asf) and male sexual dysfunction (Optale et al, 2004).

Virtual reality environments seem particularly suited to exposure therapy (Emmelkamp et al, 2002), but they have also been used to provide training, for example social skills training for people with Asperger syndrome (Parsons \& Mitchell, 2002). Virtual reality sites created for many of these purposes suffer from comparison with the graphical rendering of commercial games that young people now take for granted and it seems likely that virtual reality therapy will have to be developed to the same commercial standards. One example of how this can be done is provided by a virtual reality therapy environment for veterans with combat-induced post-traumatic stress disorder (Rizzo et al, 2005). The graphics in this program were imported from Full Spectrum Warrior, a commercial game based on a combat tactical simulation whose development was sponsored by the US Department of the Army.

\section{The machine as coach}

Lifestyle coaching is developing rapidly, and is attracting more and more counsellors and psychotherapists. The aim is not to reduce mental ill health, but to improve function above average levels. By extension from sport, where coaching has usually meant increasing physical skills, coaching is used by executives, the main client population, to increase their business, managerial and personnel skills. Inevitably coaching has spread into 'stress management' and therefore into selfhelp for anxiety, depression and substance misuse. The French publishers of Psychologies magazine, in conjunction with the mobile phone company Orange, has developed a French-language SMS (text messaging) coaching in which subscribers receive a 'personalised' message each working day for a month (20 messages in all). Two programmes are currently offered, for better communication and for self-assertiveness. An example of a self-assertiveness message for a woman is 'Ce midi au restaurant, osez refuser cette table qui ne vous plait pas' ('Dining out this lunch-time, be daring and don't take the table the waiter indicates if you don't like it'). Although such self-improvement programmes are a long way from psychotherapy, one could imagine that a much more personalised prompt could be a useful adjunct to a cognitive-behavioural therapy programme, and text messaging may be one area in which e-therapy will develop the most rapidly, given the widespread use and availability of the technology.

\section{The machine as psychotherapy trainer}

Psychotherapy training generally involves four components: theoretical learning, training in mental health, supervised practice and a personal therapy or equivalent. I will consider each in turn.

\section{E-learning: surely that's dead and buried?}

Electronic approaches to theoretical learning (elearning) have been rapidly expanding in the past decade, but the ambitions of their protagonists have proved over-optimistic. Considerable investment was made in websites that would replace physical colleges and even universities. The demise of expensive learning collaborations such as the governmentsponsored UK eUniversity (UKeU), which was wound up after it attracted only 900 students after set-up costs of $£ 62$ million (Anonymous, 2006), and Fathom, a partnership between several prestigious universities and the British Library, have created a backlash against the feasibility of e-learning (for information about the history of Fathom and free access to the archived materials go to http:/ / www. fathom.com).

These projects probably failed because they made unnecessarily large initial outlays on web technology and web design, and not because, as might be thought, not enough people have access to the internet. In May 2005 statistics published by Internet World Statistics indicated that $35.5 \%$ of the 730991138 people in Europe had access to the internet, $46.9 \%$ in the European Union and $58.7 \%$ in the UK. Thus the UK was the fourth 'most internetconnected' country in the European Union, after Sweden, Denmark and The Netherlands, and the sixth in the world (http:/ / www.internetworldstats. com/stats4.htm, accessed 30.5.05).

However, it is not access alone that limits the internet's use for e-learning. There is also the perceived value of e-learning compared with face-toface learning. In a survey carried out by the University of Cologne on behalf of the European Centre for the Development of Vocational Training, $80 \%$ of the 18000 European Union citizens interviewed thought that life-long learning was important, but only just over a half were confident in using a computer $(65 \%$ of male and $52 \%$ of female respondents). Thirtyone per cent of respondents had taken part in some form of education or training during the preceding year, but only $17 \%$ had even thought of taking a course at a school, university, or college, and only $12 \%$ would consider distance learning. Even fewer would consider using the internet for collaborative learning (Chisholm et al, 2004). This is a reflection 
of a general phenomenon in internet development. New ideas and new programs are quickly taken up by a minority of 'early adopters', but then take much longer to be accepted by the majority of internet users.

People who do try e-learning often express satisfaction with it (Chisholm et al, 2004). It offers a much richer educational environment than most classroom situations. Lectures can, of course, be delivered by computers, and lectures recorded at one site can be broadcast by satellite to many linked educational centres with suitable receiving facilities or, as bandwidth has increased, broadcast over the internet. However, e-learning environments do not need to be so restricted. Text can be provided with hyperlinks in which words or phrases can be linked to definitions, further material or exercises. Images, video clips, audio clips and hyperlinks to the enormous store of web information can also be provided.

\section{Educational philosophy and e-learning}

E-learning materials are rarely nowadays just plonked onto the net. They are embedded in 'virtual learning environments' (VLEs). These provide additional facilities such as student tracking, virtual whiteboards (which enable users to write or draw with their mouse or other pointing device on a screen area visible to other users), the setting and marking of assessments, and dedicated chatrooms and discussion groups. Most UK universities have a site license for a virtual learning environment, most often either Blackboard, in which Microsoft has a stake, or webCT. There are many other virtual learning environments, often the left-overs of some single-user application, but few have been developed to high commercial standards. One of the strengths of the internet is the provision of freeware, and there are also many 'open source' (i.e. free) virtual learning environments. A comparison of one of these, Moodle, with Blackboard found that students were more satisfied with the open source program (Bos et al, 2005). This is consistent with my own experience. My colleagues and I have created a virtual learning environment specifically for delivering psychotherapy training (SEPTIMUS: see http:/ / www.psychotherapytraining.net). We have found that the flexibility it provides (it is written using Dreamweaver and incorporates templates and open source hypertext preprocessor (PHP) add-ons) superior to either Blackboard or webCT.

E-learning materials are available from a limited number of universities worldwide, from collaborations such as those that created SEPTIMUS and as short training packages. An example of the latter is rCalipso, developed by a team representing a group of US psychoanalytic organisations (Williams et al, 2001). rCalypso focuses on the teaching of therapeutic techniques (of cognitive-behavioural therapy) rather than on the underlying theory of psychotherapy, which is the topic of SEPTIMUS.

As before in this article, we seem to be arriving at the conclusion that computer-based methods are an alternative to traditional teaching, but are neither clearly superior nor inferior - at least while the computer is being used to emulate the classroom. And, as before, we are at the point where we are confronted with both the risks and the advantages of computer-based learning, which are a direct consequence of the technology.

\section{Is e-learning effective?}

Early meta-analyses of e-learning $v$. traditional learning indicate a considerable advantage of the former over the latter, but when like-for-like methods are compared (i.e. the same courses delivered by the same teachers in either e-learning or traditional formats), the differences disappear (Broudo et al, 1997). However, e-learning is no less effective than traditional learning and, for students who are distant from training centres or who have family or other commitments that prevent them from attending, it may be the only available kind of learning. E-learning also has the advantage that there is a permanent record of teachers' comments and interventions so that learners can refer back to these, if they wish.

\section{Disembodiment, again}

Computers, as we have seen, do not support the embodiment, the presence, that classrooms do. I have already considered the implications of this for self-revelation (Tantam, 2006b). Although at the moment the main medium continues to be text, increasing bandwidth is making videoconferencing more feasible. (Even text messaging is increasingly being extended by video, graphics and voice-internet telephony, as is evident from the growing complexity of one of the original free messaging programs, MSN Messenger, recently relaunched as Windows Live Messenger.) Videoconferencing allows a limited kind of embodiment and the look can re-enter the repertoire of e-learning gestures - but it will be a look from which much can easily be concealed.

Even with videoconferencing, the presence or absence of a student is likely to remain more obvious in a real than in a virtual classroom. Absence or lack of participation can, as all psychotherapists know, 
conceal disengagement, emotional turmoil, anger or incipient failure. Yet for such an important sign it is easy to overlook.

Most teachers who use virtual learning environments find that maintaining the materials (pruning broken hyperlinks, finding fresh ones, and updating questions, assessments and other materials) is much harder to do, even though less time-consuming, than writing the materials in the first place. Maintaining activity and surveillance of discussion forums is also harder once the initial excitement and enthusiasm has worn off. The very fact that the activity is flexible and can be fitted in anywhere increases the chance of it always being at the bottom of the priority list. Finally, knowing that one's responses in forums or chatrooms are archived and can be retrieved puts extra pressure on those who provide teaching or therapy online.

\section{Asynchronous communication and self-directed learning}

Discussion forums, like correspondence chess, offer the possibility of interacting with others at a time, place and pace of one's choosing, but they also provide some of the communicative pressure of an internet chat (when they are used in real time (synchronously)), or they can be a bit more like an exchange of emails, with a time lag between the posting and the reply (hence, asynchronous communication). This produces a different quality of discussion than the chatroom. Replies can be more considered, hyperlinks can be added to messages, and images or documents attached. There is time for reflection.

In my experience, the discussion forum is the most visited page in an educational site. It is an opportunity for students to comment on what they are being taught and to share their ideas.

\section{The learner's control over the learning}

Vygotsky, in his day a critic and rival of Piaget and still hailed as one of the greats in developmental psychology, proposed that children learn through socialisation and not, as Piaget suggested, by the elaboration of mental structures. Teachers influenced by Vygotsky emphasise collaborative learning in which students are encouraged to learn from each other, and this approach is particularly applicable to discussion forums.

Vygotsky argued that individuals learn by extending the boundary of what they know, their 'zone of proximal development', and not by acquiring new blocks of knowledge. Each student will have a different zone of proximal development, and so one of the aims of collaborative teaching is to give the learner (the term often preferred over student, as androgogy is often preferred over paedogogy) greater control over their own learning - and over their learning environment - so as to maximise their exposure to learning opportunities that are proper to this zone.

The discussion forum does give learners a degree of control over the medium of their learning, but this can be increased by allowing students to create their own learning materials. Two key technologies for this are the wiki, which I considered in the first article in this series (Tantam, 2006a), and concept mapping.

\section{Concept mapping}

If we were to map the concepts in this article the connections between the word 'web' and other common words would be unusual and unusually frequent. If we were to display this graphically, one way would be to show the word 'web' in the centre of the screen and around it a cluster of short links to other words, for example embodiment, disinhibition, growing, accessibility and so on. This map could be compared with other maps to demonstrate that the centrality of the word 'web', its links and the closeness of its links are all idiosyncratic to the discourse used in this and perhaps a few other deviant texts (such as computing magazines). Our implicit use of such maps is one means of identifying what kind of discourse we are dealing with. So some readers who have scanned this article might have seen many instances of the word 'web', noticed how it often came up in connection with many of the ideas presented here and concluded that the article is not for them, but for 'nerds'.

The familiar London underground map created by Harry Beck in 1931 is an example of a schematic in which it is the connections between tube stations that is displayed, not their geography. A concept map, a term coined by Joseph Novak, is a schematic also based on connections, but conceptual ones. Its origins lie in Vygotsky via the assimilation theory of David Ausubel, who stressed the importance of extending new learning out from what is already known, and the constructivist teaching approach based on similar ideas. A concept map presents words or propositions and the connections between them. Connections might represent ordinality, for example in the map shown in Fig. 1, or associations (Fig. 2).

The World Wide Web provides new methods of concept mapping. For example, a concept may be represented by a web page, a connection by a user making a hyperlink jump from one page to another, and the frequency with which a particular 


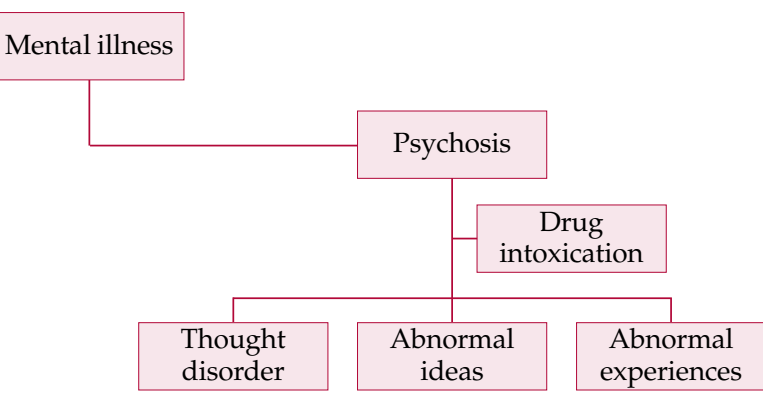

Fig. 1 A simple map of the concept 'psychosis' and its super- and sub-ordinal concepts.

jump is made by the closeness of those two pages, or concepts, on the map. Software (for a list see http:/ / ltsnpsy.york.ac.uk/conceptmapping / conceptmapping/html/software.html) simplifies the development and creation of concept maps. Microsoft's Visio can also be used for this purpose. Concept mapping has been used in a variety of ways in psychotherapy (Goodyear et al, 2005), but one of the most interesting is as a tool for learners to examine their presumptions about clients and help them to identify areas of future clinical learning. This is the basis of CoCaCo, discussed in the next section.

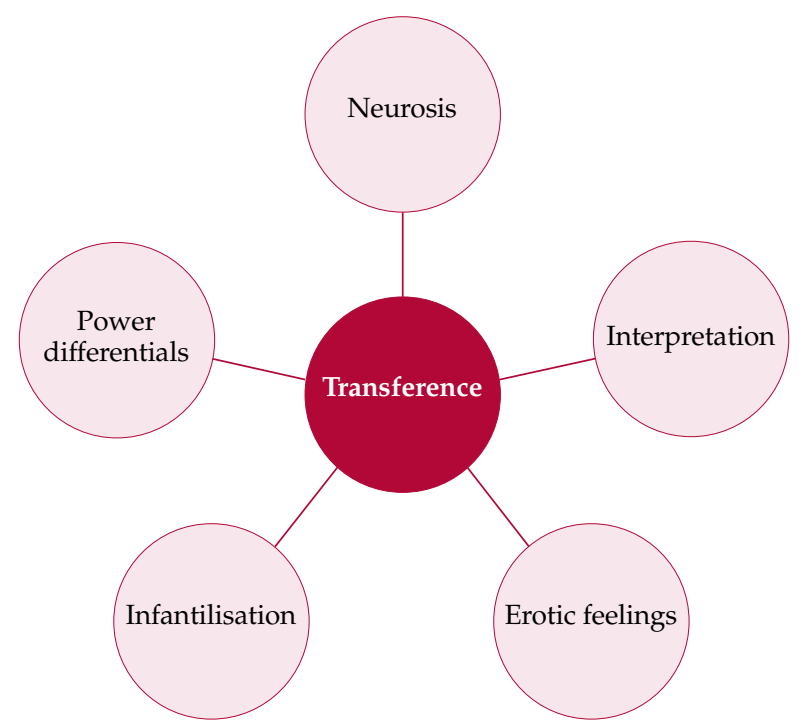

Fig. 2 An invented map of a concept and its associated concepts, based on the most frequent words given by a group asked to say what they thought of when they heard the word 'transference'.

\section{Learning about mental health: formulation skills}

\section{Mapping programs}

The CoCaCo (from 'coherence in case conceptualisations') program allows trainees to develop a case conceptualisation by drawing for them maps showing whether statements about a patient fit together (are connected) or exclude each other (are not connected). Trainees using CoCaCo developed more nuanced (more 'connected') formulations and $95 \%$ were satisfied or highly satisfied with this feature of their training (Berger, 2004).

An alternative approach to formulation is the Intensive Feedback Tool (Caspar et al, 2004), which enables text to be uploaded and analysed to produce a 'semantic map' of words that often occur together and are assumed to be semantically related. For example, 'anxiety' and 'fear' often occur together and are therefore mapped close together in the semantic space. In one application to psychotherapy training, trainees uploaded textual descriptions of videos of clinical scenarios that they had viewed. The program broke these descriptions into fragments, which were compared with the fragments of other descriptions of the same scenarios stored in a database. A similarity bar chart was produced, with a similarity index for each fragment based on the number of words which were semantically related to the words in comparable fragments in the database. These indices provided a way of seeing how close a trainee's description was to those of trainers' descriptions on the database.

\section{Virtual reality}

A technically much more complicated approach is to have trainees 'interview' a virtual patient. Software has been developed that shows on screen a representation of a head and upper torso which can model facial expressions and reproduce dialogue elements extracted from recorded psychotherapy interactions. A clinician observer rates the trainee therapist's interventions in real time and tells the simulation to 'improve' (produce more positive dialogue elements, look more positive), 'continue' (with no change in dialogue elements and no change in facial expression) or 'decompensate' (become acutely distressed or disturbed) (Beutler \& Harwood, 2004).

\section{E-supervision, e-training and e-therapy}

All of these tasks are beyond the current generation of computers. However, they can be performed 
Box 2 What does the internet hold for psychotherapy?

- The internet is set to become the dominant technology assisting communication in health and it is likely to become an indispensable tool for psychotherapists and counsellors

- Internet acceptability is currently low and is likely to grow slowly but surely

- The internet encourages anonymity and escape from the 'gaze of the other', which has advantages and disadvantages for psychotherapy and psychotherapists

- The internet enables accessibility for users who are currently unable to access psychotherapy, for example people with disabilities affecting mobility, those who are not in control of their working time, and those who are considered 'too sick' to be suitable for psychotherapy

electronically by using the electronic medium to mediate between the trainer and the trainee. It is to this situation, therefore, that I will turn in the next and last article in this series (pp. 427-431, this issue).

\section{A final word}

The internet is here to stay (see Box 2). As might be expected, the internet itself is a source of considerable information on electronic approaches in mental health in general and psychotherapy in particular. Box 3 lists some useful websites and gives details of journal special issues dedicated to technology in psychotherapy and clinical psychology.

\section{Declaration of interest}

D.T. is the author of a hyper-media distance-learning course SEPTIMUS (http:/ / www.septimus.info).

\section{References}

Alder, G. S. \& Ambrose, M. L. (2005) Towards understanding fairness judgments associated with computer performance monitoring. An integration of the feedback, justice, and monitoring research. Human Resource Management Review, 15, 43-67.

Anonymous (2006) The failure of UKeU. Computing, 6 September. http://www.computing.co.uk/computing/ specials/2071853/failure-ukeu

Bagley, C. \& Genuis, M. (1991) Psychology of computer use: XX. Sexual abuse recalled: evaluation of a computerized questionnaire in a population of young adult males. Perceptual and Motor Skills, 72, 287-288.

Berger, T. (2004) Computer-based technological applications in psychotherapy training. Journal of Clinical Psychology, 60, 301-315.

\section{Box 3 Online information and further reading}

Websites and pages

- W3Schools: http://www.w3schools.com/default.asp

Useful instructions about webpage creation and associated matters

- eTherapy: http://www.gingerich.net/etherapy.htm

Web page on e-therapy with many links to further information. Created by Wallace Gingerich (Case Western Reserve University, Cleveland, Ohio)

- PsychCentral: http://psychcentral.com

John D. Grohol's award-winning website on mental health issues

- International Society of Mental Health Online: http://www.ismho.org

Aims 'to promote the understanding, use and development of online communication, information and technology for the international mental health community'. Includes a research bibliography on online mental health interventions

- Metanoia: http://www.metanoia.org

'The mission of Metanoia is to break down barriers that keep people from getting the help they need'

Journals

- Psychotherapy Theory, Research, Practice, Training. Special issue: The technology of psychotherapy, 40 (1-2), 3-169.

- Journal of Clinical Psychology. Special issue: Technological developments and applications in clinical psychology and psychotherapy, 60, 221-349. 
Beutler, L. E. \& Harwood, T. M. (2004) Virtual reality in psychotherapy training. Journal of Clinical Psychology, 60, 317-330.

Bos, B., Munoz, K. D. \& Van Duzer, J. (2005) Blackboard vs. Moodle. A Comparison of Satisfaction with Online Teaching and Learning Tools. Arcata, CA: Humboldt State University. http:/ / www. humboldt.edu/ jdv1/moodle/all.htm

Botella, C., Hofmann, S. G. \& Moscovitch, D. A. (2004) A selfapplied, Internet-based intervention for fear of public speaking. Journal of Clinical Psychology, 60, 821-830.

Brave, S., Nass, C. \& Hutchinson, K. (2005) Computers that care: investigating the effects of orientation of emotion exhibited by an embodied computer agent. International Journal of HumanComputer Studies, 62, 161-178.

Broudo, M., White, M., Rodenburg, D., et al (1997) The effectiveness of interactive multimedia as an instructional aid for learning basic clinical skills and knowledge. In Advances in Medical Education (eds A. J. J. A. Scherpbier, C. P. M.van der Vleuten, J. J. Rethans, et al), pp. 321-326. New York: Kluwer.

Buhrman, M., Faltenhag, S., Strom, L., et al (2004) Controlled trial of Internet-based treatment with telephone support for chronic back pain. Pain, 111, 368-377.

Butcher, J. N., Perry, J. \& Hahn, J. (2004) Computers in clinical assessment: historical developments, present status, and future challenges. Journal of Clinical Psychology, 60, 331-345.

Caspar, F., Berger, T. \& Hautle, I. (2004) The right view of your patient: a computer-assisted, individualized module for psychotherapy training. Psychotherapy Theory, Research, Practice, Training, 41, 125-135.

Castelnuovo, G., Buselli, C., De Ferrari, R., et al (2004) New tools in cybertherapy: the VEPSY web site. Studies in Health Technology and Informatics, 99, 15-35.

Cavanagh, K. \& Shapiro, D. A. (2004) Computer treatment for common mental health problems. Journal of Clinical Psychology, 60, 239-251.

Chisholm, L., Larson, A. \& Mossoux, A.-F. (2004) Lifelong Learning: Citizens' Views in Close-up. Findings from a Dedicated Eurobarometer Survey. 2004. Luxembourg: Office for Official Publications of the European Communities.

Copeland, J. \& Martin, G. (2004) Web-based interventions for substance use disorders. A qualitative review. Journal of Substance Abuse Treatment, 26, 109-116.

Emmelkamp, P. M., Krijn, M., Hulsbosch, A. M., et al (2002) Virtual reality treatment versus exposure in vivo: a comparative evaluation in acrophobia. Behaviour Research and Therapy, 40, 509-516.

Epstein, J. \& Klinkenberg, W. D. (2001) From Eliza to Internet: a brief history of computerized assessment. Computers in Human Behavior, 17, 295-314.

Gardner, W. , Shear, K. , Kelleher, K., et al (2004) Computerized adaptive measurement of depression. A simulation study. BMC Psychiatry, 4, 13.

Goodyear, R. K., Tracey, T. J. G., Claiborn, C. D., et al (2005) Ideographic concept mapping in counseling psychology research: conceptual overview, methodology, and an illustration. Journal of Counseling Psychology, 52, 236-242.

Gould, R. (1989) Therapeutic Learning Program (Version 5.0). Santa Monica, CA: Interactive Health Systems.

Greist, J. H., Gustafson, D. H., Strauss, F. F., et al (1973) A computer interview for suicide-risk prediction. American Journal of Psychiatry, 130, 1327-1332.

Jacobs, M. K., Christensen, A., Snibbe, J. R., et al (2001) A comparison of computer-based versus traditional individual psychotherapy. Professional Psychology: Research and Practice, 32, 92-96.

Kaltenthaler, E., Brazier, J., De Nigris, E., et al (2005) Computerised Cognitive Behaviour Therapy for Depression and Anxiety Update: A Systematic Review and Economic Evaluation. London: NICE. http:/ / www.nice.org.uk/page.aspx?o=247657

Lucas, R. W., Mullin, P. J., Luna, C. B., et al (1977) Psychiatrists and a computer as interrogators of patients with alcoholrelated illnesses: a comparison. British Journal of Psychiatry, 131, 160-167.

McCrone, P., Knapp, M., Proudfoot, J., et al (2004) Costeffectiveness of computerised cognitive-behavioural therapy for anxiety and depression in primary care: randomised controlled trial. British Journal of Psychiatry, 185, 55-62.
Mead, A. D. \& Drasgow, F. (1993) Equivalence of computerized and paper-and-pencil cognitive ability tests. A meta-analysis. Psychological Bulletin, 114, 449-458.

Millstein, S. G. \& Irwin, C. E. (1983) Acceptability of computeracquired sexual histories in adolescent girls. Journal of Pediatrics, 103, 815-819.

National Institute for Clinical Excellence (2002) Guidance on the Use of Computerised Cognitive Behavioural Therapy for Anxiety and Depression (Technology Appraisal no. 51). London: NICE.

Optale, G., Pastore, M., Marin, S., et al (2004) Male sexual dysfunctions: immersive virtual reality and multimedia therapy. Studies in Health Technology and Informatics, 99, 165-178.

Owen, J. E., Klapow, J. C., Roth, D. L., et al (2004) Improving the effectiveness of adjuvant psychological treatment for women with breast cancer: the feasibility of providing online support. Psycho-oncology, 13, 281-292.

Parsons, S. \& Mitchell, P. (2002) The potential of virtual reality in social skills training for people with autistic spectrum disorders. Journal of Intellectual Disability Research, 46, 430-443.

Percevic, R., Lambert, M. J. \& Kordy, H. (2004) Computersupported monitoring of patient treatment response. Journal of Clinical Psychology, 60, 285-299.

Rizzo, A., Pair, J., McNerney, P. J., et al (2005) Development of a VR therapy application for Iraq War military personnel with PTSD. Studies in Health Technology and Informatics, 111, 407-413.

Saygin, A., Cicekeli, I. \& Akman, V. (2000) Turing test: 50 years later. Minds and Machines, 10, 463-518.

Tantam, D. (2006a) Computers, the internet and the World Wide Web: an introduction for the e-therapist. Advances in Psychiatric Treatment, 12, 359-367.

Tantam, D. (2006b) Opportunities and risks in e-therapy. Advances in Psychiatric Treatment, 12, 368-374.

Wainer, H. (2000) Computer Adaptive Testing: A Primer. Hillsdale, NJ: Erlbaum Associates.

Weizenbaum, J. (1966) ELIZA - a computer program for the study of natural language communication between man and machine. Computational Linguistics, 9, 36-41.

Weizenbaum, J. (1976) Computer Power and Human Reason. San Francisco, CA: W. H. Freeman

Whipple, J. L., Lambert, M. J., Vermeersch, D. A., et al (2003) Improving the effects of psychotherapy: the use of early identification of treatment failure and problem-solving strategies in routine practice. Journal of Counseling Psychology, 50, 59-68.

Wiederhold, B. K. \& Wiederhold, M. D. (2004) The future of cybertherapy. Improved options with advanced technologies. Studies in Health Technology and Informatics, 99, 263-270.

Williams, C., Aubin, S., Harkin, P., et al (2001) A randomized, controlled, single-blind trial of teaching provided by a computer-based multimedia package versus lecture. Medical Education, 35, 847-854

\section{MCQs}

\section{E-learning:}

a is less acceptable than traditional learning to those who use it

b is considered by most people to be a learning method that they might adopt

c is only useful for communicating simple ideas

d cannot have an interactive element.

\section{E-psychotherapy:}

a is not suitable for treatments where exposure is required

$\mathrm{b}$ has never been used for psychodynamic psychotherapy

c requires special technology not found in computers sold in shops today 
d may involve asynchronous communication between therapist and client.

3 Computers cannot replace people as conversational therapists because computers:

a fail the Turing test

b cannot solve problems quickly enough

c do not follow procedures

$\mathrm{d}$ are disembodied.

\section{MCQ answers}

$1 \quad 2 \quad 3$

a $\mathrm{F}$ a $\mathrm{F}$ a $\mathrm{T}$

b F b F b F

c F c F c F

d F d T d T

\section{Computers in Psychiatry} Edited by Fionnbar Lenihan

At its heart, a psychiatrist's work is about communicating. Failures in communication have led to well-publicised failures in care. It is hoped that new communication technologies will lead to better care, but to realise these hopes psychiatrists need a computer book aimed at intelligent professionals, not 'dummies'. This is that book.

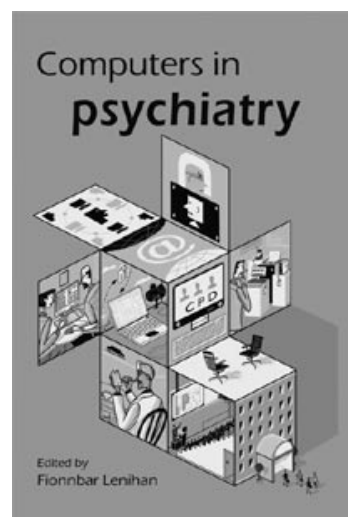

It has been written by mental health professionals for mental health professionals. After covering basic computer skills, the book focuses on areas of specific interest to psychiatrists, so that the knowledge gained can be used confidently to support psychiatric practice. The reader is shown how to use a computer for data analysis, audit, report-writing, email and presentations. Both legal and technical aspects of confidentiality and security are discussed, and forthcoming developments in National Health Service information technology are fully explained.

- Buying a computer, mobile computing, presentation software and much more.

- Legal issues and computer security.

- How to get the best from information technology in both your research and your clinical practice.

2006, 222 pages, paperback,

ISBN 1904671217 , Price $£ 22.50$

(RCPsych members' price: £20.25)

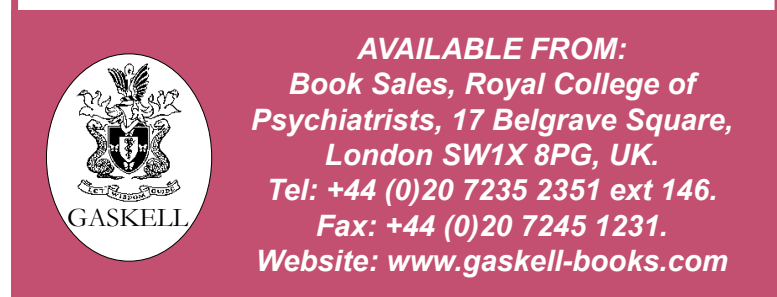

